\title{
Increased Urinary L-Histidine Concentrations in Children with Obesity
}

\author{
Li Xie $^{1}$, Wei Xie ${ }^{2 *}$, Xuejun Kang ${ }^{3}$ and Zexin Cheng ${ }^{1}$ \\ ${ }^{1}$ College of Animal Science and Food Engineering, Jinling Institute of Technology, 210038, Nanjing, China \\ ${ }^{2}$ Kebai Pharmaceutical Technology Co. Ltd, Nanjing 210044, China \\ ${ }^{3}$ Key Laboratory of Child Development and Learning Science (Ministry of Education), School of Biological Science \& \\ Medical Engineering, Southeast University, Nanjing 210096, China \\ *Corresponding author.Email: xiedoctor@yeah.net
}

\begin{abstract}
L-histidine plays an important role in the growth of infants and young children as well as positively improves insulin resistance through suppressed inflammation. The study aimed to investigate the relationship between ${ }_{\mathrm{L}}$-histidine levels and obesity and evaluate the feasibility of ${ }_{\mathrm{L}}$-histidine as an important indicator of auxiliary diagnosis for pediatric obesity. Thus, the urinary content of ${ }_{\mathrm{L}}$-histidine from 74 children with obesity and 84 normal weight were determined and analyzed in the study. Results found that the ${ }_{\text {L }}$-histidine concentration in urine (median [interquartile range] $\mathrm{mg} / \mathrm{L}$ ) was $8.29(4.42-20.70) \mathrm{mg} / \mathrm{L}$ in the children with obesity and $5.60(2.16-14.06) \mathrm{mg} / \mathrm{L}$ in the normal-weight children $(P<0.01), 5.71(2.57-17.15) \mathrm{mg} / \mathrm{L}$ in girls and $9.92(5.54-23.33) \mathrm{mg} / \mathrm{L}$ in boys $(P<0.05) . \quad$ L-histidine concentration in severe obesity children were significantly higher than that of mild obesity $(P<0.05)$. The urinary $\mathrm{L}$-histidine levels were positively correlate with BMI and the mean and median of L-histidine concentration in urine increase with children's obese levels.
\end{abstract}

Keywords: Urinary ${ }_{L}$-Histidine, Energy intake, Children with obesity

\section{INTRODUCTION}

Childhood obesity is now considered a major threat to children's health and risk factor to adult diabetes, atherosclerosis and other diseases [1]. Obesity is a common disease showing excessive body fat, and is closely associated with the disorder of lipid metabolism, which showed mainly the dysfunction of hypothalamus and peripheral energy metabolism. The mechanism of obesity is very complex and related to interactions with the unlike neurons among the process of feeding, energy consumption and fat synthesis [2-3]. In addition, studies have showed that children who were obese or overweight had increased risks of type 2 diabetes, hypertension, dyslipidemia, carotid-artery atherosclerosis and this is mainly because childhood obesity was closely related to substance metabolism such as amino acid [4].

L-histidine(L-his), which is one of amino acids and is defined as a nonessential amino acid for adult but essential for children, is conducive to the repairs of tissue repair and plays an important role in the growth of infants and young children [5]. Studies have focused that imidazole ring of ${ }_{\mathrm{L}}$-histidine is able to chelate metal ions and plays a significance role in many present-day lives such as enzyme-catalytic reactions, $\mathrm{PH}$ value adjustment and protein phosphorylation reaction [6]. In addition, early studies showed that L-histidine supplementation improves insulin resistance(IR) through suppressed inflammation in obese women with the metabolic syndrome [7]. Researchers suggested that there was a negative correlation between L-histidine intake and energy intake [8-9]. The mechanism may involve the conversion of ${ }_{L}$-histidine into histamine in the cerebrospinal fluid (CSF) [10]. Histamine plays as a neurotransmitter in central nerve system focused on weaking appetite regulation and can be synthesized through two enzymes tightly tied to -histidine decarboxylase living in the central nervous system [11-12]. As a precursor of histamine, L-histidine cannot be synthesized in the brain but transported across the blood-brain barrier by its transporter [13]. An increased level of ${ }_{L}$-histidine in the serum of individuals with obesity has been studied in previous studies, reminding that the content of $\mathrm{L}$-histidine might be served as an objective index for reflecting childhood obesity and an 
important auxiliary method in the diagnosis [14].

However, most of previous studies on the relevance between L-histidine and obesity only took adults or teenagers as objects and these test were performed on serum samples. There were very few studies to investigate the level of $\mathrm{L}_{\mathrm{L}}$-histidine of childhood obesity, especially tested on non-invasive samples. Indeed, L-histidine can be allowed the non-invasive assessment of biochemical processes in vivo such as in urine, saliva and so on [15]. The urine samples of children have the advantages of convenient sampling, easy grasping on sample quantity, safe detection, being beneficial for detection and no pollution. The aim of the present study was to determine ${ }_{\mathrm{L}}$-histidine content in urine between a group of Chinese children with obesity and normal health controls and to evaluate the feasibility of L-histidine as an important indicator of auxiliary diagnosis for pediatric simple obesity.

\section{SUBJECTS AND METHODS}

\subsection{Subjects}

This study included 74 children with obesity [average height $(119.75 \pm 5.25) \mathrm{cm}$, average weight $(33.55 \pm 13.15) \mathrm{kg}$ ] and 84 normal weight [average height $(119.75 \pm 9.25) \mathrm{cm}$, average weight $(22.45 \pm 3.95)$ $\mathrm{kg}$ ] at three kind gardens in Suzhou, China. All analyses involving human samples were approved by the Institutional Review Board of the Southeast University and informed consent from all enrolled subjects (signed by parents/guardians) were obtained.

Body mass index $(\mathrm{BMI})=$ body mass $(\mathrm{kg}) /$ body height $\left(\mathrm{m}^{2}\right)$. The children with obesity internalize standard: children were assessed by body height divided body mass recommended by WHO. Obese was judged by body mass exceeding healthy children more than $20 \%$ with equal body height and gender, 20\% 29\%, $30 \% \sim 49 \%$, above $50 \%$ more than normal children assessment mild, moderate, severe stages of obesity and exclusion congenital hereditary, metabolism, and endocrine disease. Any participant with known disorders to cause fatty and any case with syndromatic obesity was excluded.

\subsection{Urinary $L_{L}$-histidine Measurements}

Urine were collected from participants at $10 \mathrm{am}$, and was centrifuged at $4000 \mathrm{r} / \mathrm{min}$ for $5 \mathrm{~min}$ at room temperature and the samples stored at $-20^{\circ} \mathrm{C}$ before use. Approximately $0.1 \mathrm{~mL}$ urine was used to determine the content of $\mathrm{L}_{\text {-histidine by high performance liquid }}$ chromatography according to the methods established by Sukran[16].

\subsection{Statistical Analysis}

Frequencies and chi square test for categorical variables were used for descriptive analysis (Mean $\pm \mathrm{SD}$ ). The significance of differences between groups was determined using $t$ test. Non-parametric data were expressed as medians and percentiles (25th and 75th), statistical differences were determined using the Mann-Whitney $U$ test. Correlations of urinary L-histidine and BMI were analyzed using Pearson's correlations. Statistical procedures were performed using SPSS version 18 (IBM SPSS Statistics) and $p<$ 0.05 was reported as statistically significant.

\section{RESULTS}

\subsection{Subject Characteristics}

Difference of the age of the children with obesity (5.5 \pm 1.1 years) and normal weight $(5.5 \pm 1.2$ years) was not significant $(P=0.553)$, with homogeneous distribution by sex $(P=0.443)$. The body weight and BMI in obese children were significantly higher than that of normal weight $(P<0.001)$. Obesity levels were slightly higher in boys than in girls, although this difference was not statistically significant and the BMI values did not differ between boys and girls in obese children $(P>0.05)$. The ${ }_{\mathrm{L}}$-histidine concentration in urine (median [interquartile range]mg/L) was $8.29(4.42-20.70)$ $\mathrm{mg} / \mathrm{L}$ in the children with obesity and $5.60(2.16-14.06)$ $\mathrm{mg} / \mathrm{L}$ in the normal-weight children $(P<0.01)$, as well as $5.71(2.57-17.15) \mathrm{mg} / \mathrm{L}$ in girls and 9.92 (5.54-23.33) $\mathrm{mg} / \mathrm{L}$ in boys $(P<0.05)$. Obviously, L-Histidine is more accumulated in obese children, eapecially for obese boys (Table 1). 
Table 1. Characteristics of the Normal Weight and Obese Children

\begin{tabular}{|c|c|c|c|}
\hline Groups & Normal-weight $(n=84)$ & Obese $(n=74)$ & $P$ value \\
\hline Age $^{\mathrm{a}}$, years & $5.5 \pm 1.2$ & $5.5 \pm 1.1$ & 0.553 \\
\hline $\begin{array}{l}\text { Sex }, \% \\
\text { Female } \\
\text { Male }\end{array}$ & $\begin{array}{l}35(41.67) \\
49(58.33)\end{array}$ & $\begin{array}{l}27(36.49) \\
47(63.51)\end{array}$ & 0.443 \\
\hline Body weight $^{\mathrm{a}}, \mathrm{kg}$ & $22.45 \pm 3.95$ & $33.55 \pm 13.15$ & $<0.001^{*}$ \\
\hline Body height ${ }^{\mathrm{a}}, \mathrm{cm}$ & $119.75 \pm 9.25$ & $119.75 \pm 5.25$ & 0.926 \\
\hline $\mathrm{BMI}^{\mathrm{a}}, \mathrm{kg} / \mathrm{m}^{2}$ & $15.43 \pm 1.45$ & $22.00 \pm 2.10$ & $<0.001 *$ \\
\hline L-His ${ }^{\mathrm{c}}, \mathrm{mg} / \mathrm{L}$ & $5.60(2.16-14.06)$ & $8.29(4.42-20.70)$ & $0.005^{*}$ \\
\hline Obese children & Girls $(n=27)$ & Boys $(n=47)$ & $P$ value \\
\hline $\mathrm{BMI}^{\mathrm{a}}, \mathrm{kg} / \mathrm{m}^{2}$ & $21.66 \pm 2.12$ & $22.19 \pm 2.09$ & 0.296 \\
\hline $\mathrm{L}-\mathrm{His}^{\mathrm{c}}, \mathrm{mg} / \mathrm{L}$ & $5.71(2.57-17.15)$ & $9.92(5.54-23.33)$ & $0.045^{*}$ \\
\hline $\begin{array}{l}\text { Obesity levels }{ }^{\mathrm{b}}, \% \\
\text { mild obesity } \\
\text { moderate obesity } \\
\text { severe obesity }\end{array}$ & $\begin{array}{l}16(59.26) \\
7(25.93) \\
4(14.81)\end{array}$ & $\begin{array}{l}17(36.17) \\
18(38.30) \\
12(25.53)\end{array}$ & 0.075 \\
\hline
\end{tabular}

${ }^{\mathrm{a}}$ Mean $\pm \mathrm{SD}, \mathrm{t}$ test; ${ }^{\mathrm{b}} \mathrm{n}(\%)$ chi square test; ${ }^{\mathrm{c}}$ Median (25th and 75 th percentile) Mann-Whitney U test. *Statistical difference $(\mathrm{p}<0.05)$.

\subsection{Correlation between BMI and ${ }_{\text {-Histidine }}$}

The urinary L-histidine levels positively correlated with BMI in obese children $\left(\mathrm{r}=0.3393,{ }^{*} p=0.002\right)$ as well as normal-weight chlidren ( $\mathrm{r}=0.0662$, ${ }^{*} p=0.5622$ ), while obviously more correlated with obese ones (Figure 1). The mean and median of $\mathrm{L}$-histidine concentration in urine increase with obese levels. In addition, L-histidine concentration was significantly higher in severe obesity than mild obesity $(P<0.05)$, while there was no significant difference between mild and moderate obesity. Besides, the minimum and maximum of $\mathrm{L}_{\mathrm{L}}$-histidine concentration for severe obesity are $1.95 \mathrm{mg} / \mathrm{L}$ and $60.84 \mathrm{mg} / \mathrm{L}$ respectively, which changes much wider than other levels (Figure 2).

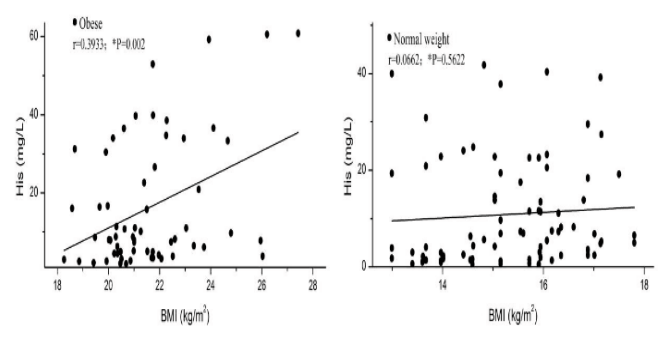

Figure 1 Correlation between His (mg/L) and BMI $\left(\mathrm{kg} / \mathrm{m}^{2}\right)$ in obese and normal-weight children.

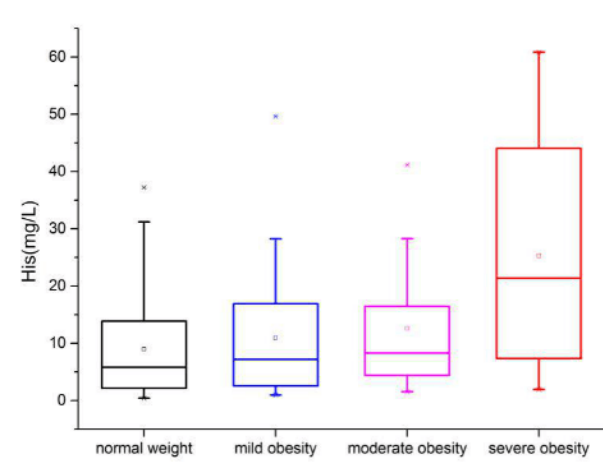

Figure 2 Histidine $(\mathrm{mg} / \mathrm{L})$ in mild obesity $(\mathrm{n}=33)$, moderate obesity $(n=25)$, severe obesity $(n=16)$ and normal-weight children ( $\mathrm{n}=84$; median, Q1-Q3, minimum, maximum). *, $\mathrm{P}<0 \quad .05$ compared to normal-weight children, one-way ANOVA after logarithmic transformation.

\section{DISCUSSION}

This case-control study showed that the urinary L-histidine levels in the obese children subjects were significantly higher than normal weight ones (especially for obese boys, which is much higher than obese girls), and the increase of urinary L-histidine levels was positively correlate with BMI values. From an overall perspective, the mean and median of L-histidine concentration in urine increase with obese levels. But there's a wide variation range, especially in severe obesity, depending in part on individual intake and utilization rate of $\mathrm{L}_{\mathrm{L}}$-histidine as it is an essential amino acid for children.

It is the first time to show increased urinary L-histidine in obese children to our knowledge. Early studies only showed that ${ }_{\text {L-histidine supplements can }}$ 
ameliorate obesity related index (BMI, waist circumference and body fat volume), insulin resistance and inflammation and oxidative stress in metabolic syndrome [17]. In the children population, low histamine levels can cause increased appetite and weight gain and also are positively correlated with homeostasis model assessment for insulin resistance (HOMA-IR) and serum leptin [18-20]. Besides, L-histidine is the only amino acid that could induce hypercholesterolemia. The most likely reason is high concentration of L-histidine in cells could inhibit the activity of acetyl coenzyme A carboxylase and fatty acid synthase, and extra amount of acetyl coenzyme A which is an essential building block for cholesterol [21]. Current insulin resistance is considered an independent risk factor for cardiovascular disease, and hypertension, metabolic syndrome, type 2 diabetes, atherosclerosis, and many other diseases [22], but the mechanism is

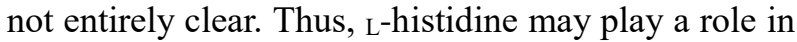
the hypercholesterolemia and insulin resistance, which can be observed in obesity. While it is still unclear that whether chronically increased $\mathrm{L}_{\mathrm{L}}$-histidine concentrations are cause or consequence of obesity formation.

The limitations of this study include the relatively small sample size of groups. Future studies with larger sample sizes are needed to evaluate the

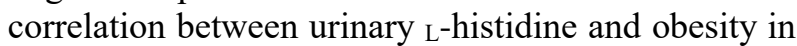
children. Besides, there were no dietary survey conducted to evaluate macro-nutrient consumption which is necessary to establish the association of L-histidine with the diet. However, this study confirmed and complemented the results of urinary L-histidine in the obese children by case-control study.

In conclusion, obese children have much higher urinary L-histidine concentration compared with normal-weight children, which may provide a novel target for obesity treatment in children.

\section{CONCLUSION}

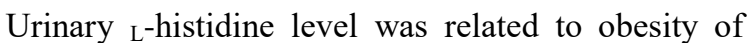
children, which may provide a novel target for future obesity treatment in children.

\section{AUTHORS' CONTRIBUTIONS}

$\mathrm{Li} \mathrm{Xie}$ contributed significantly to analysis, manuscript preparation;

Wei Xie collected the samples and performed the experiment;

Zexin Cheng contributed to the conception of the study;

Xuejun Kang helped perform the analysis with constructive discussions.

\section{ACKNOWLEDGMENTS}

This study was supported by the Key Research and Development Plan for the Ministry of Science and Technology (2018YFF0215204); the National Natural Science Foundation of China (No. 81673230); The Key Discipline Project of Animal Husbandry of Jinling Institute of Technology;

\section{REFERENCES}

[1] Y. Liang, D. Hou, X. Zhao. Childhood obesity affects adult metabolic syndrome and diabetes. Endocrine, 2015, 50(1), pp.87-92. DOI: 10.1007/s12020-015-0560-7.

[2] S. Attoub, L. Moizo, I Sobhani, et al. The H3 receptor is involved in cholecystokinin inhibition of food intake in rats. Life Sci,2001,69(4), pp.469478. DOI:10.1016/S0024-3205(01)01138-9.

[3] T.W. Lovenberg, B.L. Roland, S.J Wilson, X.X. Jiang, M.G. Erlander. Cloning and functional expression of the human histamine $\mathrm{H} 3$ receptor. Mol Pharmacol,1999, 55(6), pp.1101- 1107. DOI: $10.1124 / \mathrm{mol} .55 .6 .1101$.

[4] X.Y. Zhang, B.J. Fu, L.Z. Zhou. Study on leptin, insulin and their relationships in simple obese children. Chin J Public Health 2003,19(6), pp.657-658. DOI: 10.1177/153537020222700111.

[5] M. Togashi, E. Okuma, H. Abe. HPLC determination of N-acetyl-L-histidine and its related compounds in fish tissues. Fisheries Science, 1998, 64(1), pp.174-175. DOI:10.2331/fishsci.64.174.

[6] Y. Hu, Q. Wang, C.B. Zheng, L. Wu, Y. Lv. Recyclable decoration of amine-functionalized magnetic nanoparticles with $\mathrm{Ni2}+$ for determination of histidine by photochemical vapor generation atomic spectrometry. Analytical Chemistry, 2014, 86(1), pp.842-848. DOI:10.1021/ac403378d.

[7] R.N. Feng, Y.C. Niu. X.W. Sun, Q. Li, C. Zhao, C. Wang, F.C. Guo, C.H. Sun, Y. Li. Histidine supplementation improves insulin resistance through suppressed inflammation in obese women with the metabolic syndrome: a randomised controlled trial. Diabetologia, 2013, 56, pp.985994. DOI:10.1007/s00125-013-2839-7.

[8] H. Okubo, S. Sasaki. Histidine intake may negatively correlate with energy intake in human: a cross-sectional study in Japanese female students aged 18 years. J Nutr Sci Vitaminol, 2005, 51, 
pp.329-334. DOI:10.3177/jnsv.51.329.

[9] S. Kasaoka, N. Tsuboyama-Kasaoka, Y. Kawahara, et al. Histidine supplementation suppresses food intake and fat accumulation in rats. Nutrition, 2004, 20, pp.991-996. DOI: 10.1016/j.nut.2004.08.006.

[10] H. Yoshimatsu, S. Chiba, D. Tajima, Y. Akehi. Histidine suppresses food intake through its conversion into neuronal histamine. Exp Biol Med, 2002, 227, pp.63-68. DOI:10.1046/j.0014-2972.2001.00955. x.

[11] E.N. Marieb. Human anatomy \& physiology. The American Journal of Nursing, 1972, 57(4), pp. 414. DOI:10.1525/abt.2014.76.9.11c.

[12] H.H. Andersen, J. Elberling, L. Arendt-Nielsen. Human surrogate models of histaminergic and non-histaminergic itch. Acta Dermato-Venereologica, 2015, 95, pp.771-7. DOI:10.2340/00015555-2146

[13] J. Yamakami, E. Sakurai, T. Sakurada, K. Maeda, N. Hikichi. Stereo selective blood-brain barrier transport of histidine in rats. Brain Res, 1998, 812, pp.105-12. DOI:10.1016/S0006-8993(98)00958-5.

[14] W. Song, S. Li, M. Zhang. Analysis of amino acids in the serum of children troubled with simple obesity. Chinese Journal of Child Health Care, 2011, 19(4), pp.324-327.

[15] Fornace, J. Albert, J. Steven, Laiakis, C. Evagelia, Brenner, J. David. Assessment of Saliva as a Potential Biofluid for Biodosimetry: A Pilot Metabolomics Study in Mice. Radiat Res, 2016, 186 (1), pp.92-97. DOI:https://doi.org/10.1667/RR14433.1.

[16] A.O. Sukran, Y. Mehmet. Phytoextraction of lead and its relationship with histidine in six plant species using ICP-MS and HPLC-MS. 2016, 32(4), pp.346-356.

DOI:https://doi.org/10.1080/02757540.2016.11429 79.

[17] R.N. Feng, Y.C. Niu, X.W. Sun, et al. Histidine supplementation improves insulin resistance through suppressed inflammation in obese women with the metabolic syndrome: a randomised controlled trial. Diabetologia, 2013, 56, pp.985-994. DOI:10.1007/s00125-013-2839-7.

[18] S. Toshiie, Y. Hironobo, K. Mamoru. Hyposhalamic Neuronal Histamine: Implications of its Homeostatic Control of Energy Metabolism. Nutrition, 1997, 13(5), pp.403-411. DOI:10.1016/S0899-9007(97)91277-6.

[19] A. Lecklin, L. Tuomisto. Inhibition of histamine catabolism suppresses fat intake but not the intake of carbohydrates and protein. Inflammation Research, 2002, 51(1), pp. S53-S54. DOI:10.1007/PL00022445.

[20] T. Kazuhiko, S. Hiroaki, I. Tomoo, et al. Targeted disruption of $\mathrm{H} 3$ receptor result in changes in brain histamine tone leading to an obese phenotype. J Clin Inves, 2002,110(12), pp.1791-1799. DOI:10.1172/JCI200215784.

[21] L. He, Y. Wang, W. Liang, D.Y. Chen. Insulin resistance in obese accompanying hypercholesterolemia patients. Anatomy Research, 2010,32(3), pp.193-199.

[22] G. Uwaifo, E.M. Fallon, J. Chin, et al. Indices of insulin action, disposal, and secretion derived from fasting samples and clamps in normal glucose-tolerant black and white children. Diabetes Care, 2002, 25(11), pp.2081-2087. DOI:10.2337/diacare.25.11.2081. 